\title{
El desarrollo institucional del Ministerio de Hacienda y Comercio en el siglo XIX
}

Recibido: 23/05/19

Aprobado: 04/08/19

Carlos Morales Ceron

Universidad Nacional Mayor de San Marcos cmoralesc@unmsm.edu.pe

\begin{abstract}
RESUMEN
El Ministerio de Hacienda y Comercio, hoy Ministerio de Economía y Finanzas (MEF), fue la institución decisiva que en el siglo XIX, no solo determinó la formación de las finanzas republicanas, sino también la formación del Estado caudillista. Por la contabilidad del Ministerio de Hacienda se filtraba todo el gasto público y por la voz de sus ministros se difundía el pensamiento económico de la época, siempre en relación con los mercados internacionales, en épocas de auge y crisis. Comprende: Estudio institucional del Ministerio de Hacienda y Comercio, el comportamiento de la economía republicana en el siglo xIx, en el contexto de los gobiernos que a nuestro juicio fueron los más importantes, por ser determinantes para la época, analizamos las memorias de los principales ministros de Hacienda y Comercio en los gobiernos de San Martin, Simón Bolívar (1821-1826), gobiernos de Ramón Castilla (1845-1862)
\end{abstract}

Palabras clave: Ministerio de Hacienda y Comercio, fiscalidad, instituciones, economía.

\section{The institutional development of the Ministry of Finance and Commerce in the XIX century}

\begin{abstract}
The Ministry of Finance and Commerce (today the Ministry of Economy and Finance (MEF), was the decisive institution that in the 19th century, not only determined the formation of republican finances, but also the formation of the caudillo state. All public expenditure was filtered, and by the voice of its ministers the economic thought of the time was disseminated, always in relation to international markets, in times of boom and crisis, including: Institutional study of the Ministry of Finance and Commerce, the behavior of the republican economy in the nineteenth century, in the context of the governments that in our opinion were the most important, being determinants for the time, analyzed the memories of the main ministers of Finance and Commerce in the governments of San Martin, Simón Bolívar (1821-1826), governments of Ramón Castilla (1845-1862)
\end{abstract}

KeYwords: Ministry of Finance and Commerce, taxation, institutions, economy. 


\section{Introducción}

$\mathbf{E}$ n el presente trabajo se realiza un estudio histórico particulardelMinisterio deHacienda y Comercio, hoy Ministerio de Economía y Finanzas (MEF), la investigación se justifica por la necesidad de conocer el funcionamiento de las instituciones republicanas del Perú en el siglo XIX. Es necesario agregar que siendo las instituciones entidades que dan forma a la interacción humana, estructuran las reglas de juego en una sociedad y afectan el desempeño de la economía de un país (D. North, 1992) por lo que es básico su estudio para aplicar políticas de todo tipo. A partir de esta precisión se busca comprender el comportamiento de la economía republicana en el siglo xIX, además para entender esta relación (entre fiscalidad y economía), se hace un estudio aproximado de algunas políticas económicas implementadas. La investigación es de naturaleza descriptiva y establece una relación entre la institución ministerial y la política económica republicana del siglo Xix, de manera específica los años correspondientes entre 1821 y 1860. Los objetivos de la investigación son en principio realizar una historia institucional del Ministerio de Hacienda y Comercio y demostrar que en el siglo xIx su organización y gestión administrativa fue determinante para el manejo de la política económica y la construcción del Estado republicano.

En tal sentido, el Ministerio de Hacienda y Comercio como entidad pública, expresa desde su nacimiento en el periodo post independiente el intento de las elites peruanas constituir un Estado nacional fuerte y soberano. Este hecho se basa en que su cuerpo directivo (los ministros de Estado) pertenecía al sector oligárquico dominante.

El contexto histórico del desarrollo histórico ministerial es el siglo XIX, el cual es considerado por el dependentismo como una época en donde el estado careció de una clase dirigente, por la tardía consolidación de la vocación atlántica comercial y la constitución del Estado como sistema de poder, por la inversión británica y la guerra con Chile, (Bonilla, 1980). Según Jorge Basadre el siglo xix fue un siglo nefasto para el Perú al producirse una gran inestabilidad política nacional e internacional, por las luchas entre los caudillos políticos -,militares, y una fuerte conflictividad social, hechos que habrían sido nefastos para la construcción de la nación haciendo fracasar la promesa de la independencia peruana (Basadre, 1947). El fenómeno político conocido como caudillismo militarista habría impedido la aplicación de políticas públicas de alcance nacional.

La formación de la nación y cultura política republicana en el siglo XIX es sustancial para comprender la denominada promesa de la vida peruana enunciada por Jorge Basadre. La época fue en sus términos un siglo de fracasos por los graves conflictos internos y externos que padeció el pueblo como país incipiente luego del proceso de la independencia.

El Ministerio de Hacienda fue la institución decisiva en el maneo de las políticas económicas, sus funciones como institución proviene de la antigua institución virreinal: La Real Hacienda. En cuanto al método El estudio del Ministerio de Hacienda y Comercio es de naturaleza descriptiva, utilizamos este método para describir el comportamiento del Ministerio de Hacienda Comercio por dos razones: el primero es por tratarse de una realidad histórica ya dada, en segundo lugar por el contexto político del siglo XIX (el caudillismo y la corrupción) y la política económica que perfiló. En cuanto al uso de las fuentes (tratados, fuentes, constituciones), la base del estudio lo componen las memorias de los Ministros de Hacienda y Comercio. Los resultados muestran que los ministros formularon políticas económicas que intentaron modernizar el país, las finanzas públicas y por intentar conectar al país con los mercados internacionales, es decir el Perú fue parte de un proceso global propios del siglo XIX, auspiciado por las grandes potencias mundiales en la época del capital monopólico financiero. Las medidas aplicadas fueron necesarias para la infraestructura productiva en beneficio de las elites republicanas.

En cuanto al impacto económico de la actividad ministerial sus resultados han sido estudiados por diversos autores. En cuantos a los resultados, la historiografía peruana y extranjera revela un contexto económico republicano dividido en varias etapas. Las fuentes teóricas sobre la historia económica, muestran estudios que intentaron aproximarse al fenómeno estudiado desde el ámbito de la economía y la fiscalidad. En la actualidad, destacan los estudios de Carlos Contreras (2012) y la importancia del mercado externo, Miriam Salas y los factores internos(2016), Alfonso Quiroz y el origen fiscal republicano (2017), 
Jaime Salinas sobre el papel que cumplió la prensa: El Comercio (2018). A este grupo de autores nacionales contemporáneos se deben agregar los trabajos antiguos de Ernesto Yepes del Castillo (1981), Javier Tantaleán Arbulú y las finanzas del estado caudillista (1983), Heraclio Bonilla y el dependenstismo (1974). Otro grupo de autores lo constituyen Paul Gootemberg (1998), Rosemary Thorp y G. Bertram (1978) y Shane Hunt (2011).

\section{Resultados}

\section{Capitulo 1. Precisiones conceptuales. Teoría y} realidad del Ministerio de Hacienda y Comercio

De la Real Hacienda al Ministerio de Hacienda y Comercio. A continuación muestro un resumen de la Real hacienda virreinal: Instituida en el siglo XVI mediante el proceso de conquista, la Real Hacienda fue la institución destinada a controlar vía el cobro de impuestos todas las actividades económicas en el virreinato del Perú. La organización tributaria se produjo mediante el establecimiento de las cajas reales u oficinas fiscales encargadas de la recaudación a cargo de un cuerpo de funcionarios selectos denominados oficiales reales quienes tenían autonomía respecto a otros. Para controlar la economía en su totalidad, se fueron estableciendo un conjunto de instituciones que actuaban e manera complementaria con el Estado a través de las cajas. En 1568 se estableció la Casa de Moneda, en 1592 se fundó el Tribunal del Consulado de Lima, en 1605 se estableció el Tribunal mayor de Cuentas. El organismo contralor de la entidad fue la Junta de Hacienda establecida según Francisco López de Caravantes (Archivo Ministerio Relaciones Exteriores) en el gobierno del pacificador Don Pedro de la Gasca. Años más tarde fue reorganizada por el virrey Francisco de Toledo y en el siglo xviII fue reorganizada como Junta Superior de Real Hacienda. El nombre de la institución también cambio, en el siglo XviII la caja real matriz que recaudaba los impuestos y recibía lo que remitían las demás cajas fue denominada como Contaduría Mayor del Ejército y Real Hacienda, y, la Real Hacienda como institución fue denominada como Ministerio de Real Hacienda. En cuanto al personal, los oficiales reales fueron los guardianes de los ingresos del fisco, su relación solo era directa con el Monarca o con el Consejo de Indias (Morales 2013). Dichos funcionarios tenían que ser fieles al rey, poseer buena conducta entre otras cualidades. Para el año 1813 las cajas reales comenzaron a ser denominadas cajas nacionales, lo cual indicaba una nueva forma de concebir el país.

Al finalizar el régimen colonial, la economía fiscal se encontraba paralizada al ser la guerra de la independencia catastrófica, sus orígenes los tenemos en las reformas borbónicas, teniendo como hechos relevantes las reformas que ocurrieron en el ámbito fiscal desde el año 1760 que corresponden a una etapa liberal. Las políticas de libre comercio en el rubro comercial, monetario y fiscal implementadas en la segunda fase de las reformas borbónicas fueron determinantes para procurar una separación política definitiva de la monarquía (Lazo: 2006: I). La transición hacia la república no fue pacífica, hasta el final del régimen las autoridades coloniales tenían alguna esperanza. A pesar que el Ministerio de Hacienda había reemplazado a las atribuciones de la antigua Real Hacienda, hasta 1826, la Real hacienda dictaminaba órdenes y notas haciendo ver que la causa del rey aún existía.

Según Jorge Basadre (1963), la estructura administrativa del Perú en estos primeros años de la república se caracterizó principalmente por una organización «administrativa formalista, en la que los ropajes republicanos cubrían a veces la realidad de la tradición colonial. En la vida burocrática había insipiencia. En 1828 el presidente de la república tuvo cuatro edecanes y dos capellanes. Los ministerios eran tres: Gobierno y relaciones exteriores, con once empleados; el Ministerio de Guerra y Marina con trece y, el Ministerio de Hacienda y Comercio con doce. Las finanzas mostraban deficiencias. Luego del motín de balconcillo (golpe de estado) su presidente Riva Agüero comenzó a gestionar los primeros empréstitos con Inglaterra antes de sus destitución por el congreso, más tarde como indica Basadre, siendo comisionado de Orbegoso en Chile negocio otros empréstitos (Basadre, 1930: II. 35).

\section{Teoría sobre el Ministerio de Hacienda y Comercio}

El Ministerio de Hacienda y Comercio fue la institución fundamental para la construcción el Estado y la política republicana, por sus manos 
pasaban todas las cuentas del Estado y disponía de los ingresos de toda la política gobernante. Para Hipólito Unanue primer ministro de hacienda su existencia era fundamental para la existencia de toda la estructura política administrativa: «sin hacienda no hay Estado porque esta es el alimento y la sangre del cuerpo político» (Memoria del Ministerio de Hacienda y Comercio 1825).

Se ha descubierto que el primer estudio sobre el ministerio lo realizo Rolando Coello Caparó empleado del ministerio con el puesto de jefe del departamento administrativo de la Dirección General de Administración de Hacienda. El cargo administrativo que desempeñaba le permitió realizar un trabajo minucioso sobre la institución. Aparte de los datos históricos encontrados en el archivo del Ministerio de Hacienda, hizo el estudio más completo sobre su organización (Boletín del Ministerio de Hacienda: 1965: 30). El estudio de Rolando Coello destaca por contener en su monografía organigramas completos sobre las distintas oficinas ministeriales. Es un estudio técnico que según la descripción hallada muestra todas las oficinas y el correspondiente flujo de información.

Jorge Basadre fue unos de los primeros historiadores en estudiar las instituciones republicanas. Basadre percibió claramente el peso de la herencia de la institucionalidad colonial, observo que los primeros políticos republicanos (de raigambre colonial), estuvieron empeñados en constituir un gobierno republicano diferente. Según el autor los ministerios nacen en la época republicana como Secretarías de despacho, en el contexto de las guerras por la independencia. Todas ellas al mando de la autoridad política: el protector José de San Martín.

Teniendo una herencia virreinal, el Ministerio de Hacienda y Comercio conservaba una estructura similar por no decir igual a la antigua Real Hacienda. La contabilidad era parecida, el caso se agravaba más aun porque el virrey había saqueado las arcas del Estado y se había producido un incendio en las oficinas del palacio gubernamental que fue sede de casi todas las principales instituciones. La información oficial del estado virreinal provenía de la máxima autoridad: el virrey, quienes dejaban en sus memorias el funcionamiento de toda la administración incluida la de hacienda.

Con el cambio de régimen, la información oficial quedaba descentralizada administrativamente.
El ministro de Hacienda era ahora el encargado de trasmitir la información oficial de su despacho a la población representada en el congreso. A partir de 1822 se publican las memorias presentadas por los primeros ministros.

Según Mariano Felipe Paz Soldán el estado republicano se forma por orden del protector San Martín con tres ministerios: Gobierno y Relaciones, Guerra y Marina, y Hacienda y Comercio creados por decreto del 3 de agosto de 1821 .

Los documentos de hacienda continuaron su flujo normal de documentos, la labor no fue interrumpida, el Ministerio continuaba la labor de antiguo Ministerio de Real Hacienda, el principal cambio provendría con la gestión del ministro José María de Pando en 1830.

La guerra de independencia pudo influir en descentralizar la información fiscal hacia la población, aunque también cabe la posibilidad de que el parlamento tuviese una información más concreta sobre las finanzas del nuevo estado que se estaba formando. Ante la falta de dinero para pagar a las tropas y tener un conocimiento exacto en el gasto fiscal las memorias de hacienda permitirían saber el estado económico de la república y así poder dictar las medidas necesarias.

En cuanto a las atribuciones, el ministerio de hacienda estaba facultado en conocer y dictaminar sobre la recaudación e inversión de las rentas públicas ordinarias y extraordinarias, el funcionamiento y producción de marcos de plata acuñadas en la saqueada casa de moneda, administrar los bienes del estado y cumplir con pagar la deuda interna y externa.

Luis Benjamín Cisneros En sus datos estadísticos muestra que la economía de la república había crecido por su vinculación con los mercados internacionales. En sus estadísticas indica que en 1820 se importó 8.079.000 pesos, en 18529.382.650. En lo respectivo a la exportación en 1820 se exporto 6.254 .000 pesos y en 1852 10.086.774 (Cisneros, 1939: III. 13).

\section{Identidad institucional ministerial de los empleados de hacienda}

En la época virreinal los funcionarios y empleados de las distintas instituciones tenían por costumbre protege sus fueros e identificarse de manera irrestricta con la institución en donde laboraban. La independencia cambio la dirección política de una autoridad 
por otra, pero las costumbres políticas, las liturgias del poder y el accionar socio- cultural se mantuvieron vigentes. Militares, empleados y sacerdotes vestían cada uno de manera singular en cuanto el tipo forma y color de sus trajes. La gran variedad de trajes de los empleados de del Tribunal Mayor de Cuentas, del de Minería, del Consulado, de la Aduana, etc. fue el motivo para que el ministro Hipólito Unanue decretase que todos los empleados utilicen un uniforme oficial. (Boletín Archivo Histórico: 1960.1.18)

De acuerdo al decreto de 27 de agosto d 1821, no se podía distinguir con exactitud entre los empleados del ministerio de hacienda las jerarquías inherentes a su mando en cada una de las oficinas y de los órganos de línea. Ningún empelado llevaba distintivo alguno que los identificaba como tal. La vestimenta que se usaría a partir de la fecha consignada disponía que los empleados según su jerarquía vistieran lo siguiente:

- En general todos los empleados del ministerio usaran casaca azul, centro y vuelta anteada.

- Los Jefes máximos usarían casaca azul, centro y vuelta anteada, más dos soles de oro bordados a los extremos del cuello de la casaca, enlazados con una cadena bordada del mismo metal y matizada de estrellas más un ojal de oro en la vuelta de la casaca.

- Los oficiales mayores vestirían el mismo uniforme con la diferencia que los bordados serian de plata.

- Los oficiales primeros llevarían el bordado de plata en el cuello sin lo ojales de la casaca.

- Los oficiales segundos y terceros usaran el ojal de plata sin el bordado del cuello.

- Los empleados de inferior clase tendrían el uniforme indicado sin bordado alguno.

Es evidente que en esta jerarquía de distintivos según el puesto, se tenía como objetivo trasmitir un mensaje político institucional entre los empleados para respetar las jerarquías de mando y la estamentalidad de cada puesto consignado. Todos los uniformes serian de azul pero en la solapa el color ante, color que también debían llevar los libros de hacienda en su empastado.

En cuanto a las instalaciones del ministerio, con el cambio de régimen aún se encontraba en pie. Sin embargo luego del reingreso de las tropas del virrey La Serna, toda su infraestructura fue deshecha.

\section{El archivo histórico del Ministerio de}

Hacienda y Comercio

Al proclamarse la independencia San Martin creo por decreto protectoral los tres ministerios de estado el 3 de agosto de 1821. El archivo del ministerio de hacienda y comercio era el único que tenía sus fondos bien resguardados, esta realidad explica que para las autoridades coloniales y republicanas, lo más importante en la administración fiscal. Por fortuna el archivo se encontraba distribuido en varios locales que impidieron su destrucción: una parte se encontraba en el local perteneciente al antiguo Tribunal Mayor de Cuentas situado en la calle de la moneda, otra parte de los documentos se hallaba en el sótano de la plazuela Gastańeta, en cuanto a los libros de hacienda estos se encontraban situados en el sótano del local del Ministerio de Hacienda y Comercio. Finalmente una parte se custodiaba en los sótanos del local de Palacio de Justicia. (Boletín del Ministerio de Hacienda, 1964:3).

Fundada la república, el primer archivero del Estado formalmente fue el archivero del Ministerio de Hacienda y Comercio. El cargo fue por nombramiento que hizo Hipólito Unanue (Primer ministro de la institución). El cargo recayó en José de la Torre Ugarte, quien obtuvo el cargo el 8 de noviembre de 1821. Más tarde José de la Torre Ugarte seria el autor de las letras del Himno nacional. Los primeros años del archivo del ministerio fueron difíciles, la guerra de independencia amenazaba de manera constante el ser de la institución: el archivo, ya que contenía toda la información fiscal desde la época del virreinato y las cajas reales de provincias (ahora con la nueva denominación Tesorerías departamentales)

Con la salida del virrey José de la Serna de la capital, se produjeron incendios dentro del palacio de gobierno afectando los archivos gubernativos. El archivo del ministerio amenazaba tal suerte. Aunque no fueron muchos el virrey La Serna se llevó algunos libros de caja para consignar los gastos del gobierno paralelo virreinal que no aceptaba la derrota del virrey ni el cambio de régimen colonial al republicano.

Clasificación de los ministerios de Estado en el siglo XIX Los Ministerios y ministros de Estado en el derecho fueron considerados como los órganos superiores de la administración, los funcionarios (los ministros) unidos con el presidente de la republica ejercen 
el poder ejecutivo (León, 1897:132). Siendo los ministros responsables de sus actos en su respectivo sector, estaban obligados a ejecutar lo dispuesto por la política general del gobierno. De acuerdo a los principios del derecho administrativo en el siglo XIX, en la jerarquía del poder político los ministros de Estado ocupaban el primer rango después del jefe de estado, eso explica la importancia de dichos funcionarios en general.

El derecho administrativo en el siglo xIx clasificaba los ministerios por las atribuciones que tenía cada uno de ellos y por las necesidades del Estado de la siguiente manera:

- Las que hacen ejecutar las leyes en el interior del Estado relacionado a la administración de justicia

- Los que estaban encargados de ejecutar las leyes internacionales además de organizar el ejército y la armada.

- Los ejecutaban el gasto público y se encontraban en competencia con la legislación de Hacienda y la fortuna publica (León, 1897).

- Fines religiosos a cargo del Ministerio de Culto.

- Educación, el fin científico instrucción o educación.

- El fin económico, comercio, industria, agricultura obras públicas, administración general de fomento. Este último, corresponde al Ministerio de Hacienda.

Se admitía sub clasificaciones en cada ministerio de acuerdo a ley, la subdivisión de cada ministerios guardaban relación con la importancia que tenía cada ramo estatal.

\section{Contabilidad y contadurias del Ministerio} de Hacienda y Comercio

El régimen colonial aplico un conjunto de medidas destinadas a modernizar la contabilidad en las oficinas de todas las instituciones virreinales. Este sistema conocido como de partida doble consistía básicamente en usar libros que fiscalizaran mejor los ingresos y el gasto. El anterior sistema de partida simple de tinte domestico no funcionaba bien al momento de rendir las cuentas. En el nuevo sistema se utilizaban los libros manual diario, libro mayor y libro caja. La real cedula de 22 de julio de 1785 aplicó dicho sistema en todas las instituciones peruanas.

Cuando se estableció la república, el gobierno de San Martín decretó el 15 de agosto de 1821 que los tres primeros ministerios establecidos se distinguiesen por colores diferentes, así el Ministerio de Gobierno tendría sus libros de color blanco, el color rojo seria para los libros del Ministerio de Guerra, y color Ante para los libros del Ministerio de Hacienda y Comercio.

Con la independencia el ministerio de Hacienda (antigua real hacienda) experimento algunas modificaciones. Se establecieron varias oficinas: contabilidad, contaduría mayor de cuentas, contaduría general de contribuciones, contaduría de indios, contaduría de aduanas, contaduría general de valores, contaduría de censos, de patentes, de secuestros, etc. La Contaduría Mayor de Cuentas tenía las atribuciones de controlar en su totalidad a las administraciones del Estado. Todo lo referente al ingreso y salida de dinero y valores, sus funciones eran similares al renovado Tribunal Mayor de Cuentas. La Contaduría General de Contribuciones se encargaba de fiscalizar todas las contribuciones referidas a los predios urbanos, contribuciones personales, industriales y gremiales «en todo el país «(Boletín del Ministerio de Hacienda y Comercio, 1963: 51). El año 1830 la contaduría fue reglamentada mediante decreto supremo de 14 de agosto del mismo ańo. Sin embargo se decretó su supresión por decreto supremo de 31 de agosto de 1833. La medida provoco un aumento en el trabajo de los empleados de la Tesorería General. El contexto no era favorable debido a los conflictos provocados por las guerras civiles. Recién en 1848 las atribuciones de la contaduría extinta fueron asumidas por la Dirección General de Hacienda en el primer gobierno de Ramón Castilla.

La siguiente reorganización hacendaria se haría en el gobierno primero de Mariano Ignacio Prado. La ley del 4 de marzo de 1865 intento mejorar el servicio de la dirección. El objetivo era darle un mayor orden a las cuentas. Así se dispuso de acuerdo a ley, que la Dirección General de Hacienda centralizase todas las cuentas y llevase la contabilidad republicana y el control de los dineros mediante el sistema de partida doble. También se le encomendó elaborar el Presupuesto y tener cuidado con los bienes nacionales. (ibíd.). 
La ley del 1 de diciembre de 1868 ordeno una nueva organización ministerial. Se dispuso establecer nuevas direcciones como la Dirección de Contabilidad General y la Dirección de Crédito con tres secciones: Contabilidad General, crédito Público y Contabilidad Militar, con oficial y amanuenses. En 1886 se hizo la última reorganización de las oficinas del ministerio. Las siguientes reformas ministeriales en el ramo de hacienda se harían en el siglo $\mathrm{xx}$, a partir del año 1913.

\section{Capitulo 2. El Ministerio de Hacienda y Comercio en los gobiernos de San Martin y Simón Bolivar 1821-1826}

La iniciación de la república se encuentra enmarcada en el contexto de las guerras por la independencia. En el gobierno de San Martin se crearon tres ministerios: Estado y Relaciones exteriores, Guerra y Marina y Hacienda.

En general en 1822 se estableció lo siguiente:

- Abolición del tributo

- Establecimiento de la dirección de censos y obras pías.

- Reorganización en el cobro del derecho de anclaje

- Secuestro de la mitad de lo bienes de los españoles.

- Establecer un banco de papel moneda.

- Acuñar cuartillos de cobre como moneda provisional

- Establecimiento de la cámara de comercio del Perú.

- Casos específicos en el cobro de los derechos de cabotaje. (Dancuart, 1905: I)

El panorama era crítico según la memoria de hacienda de Hipólito Unanue (Memoria, 1822). Las cajas estaban vacías, los realistas tenían el control del callao, impidiendo el comercio. Ante su impacto social el gobierno de San Martin dispuso erradicar los impuestos extraordinarios que se habían establecido en el anterior gobierno. Para el ministro Hipólito Unanue los recursos del Ministerio de Hacienda eran el alma y el cuerpo de la república, sin él no se podían vivir. Unanue que había servido para el virrey Pezuela muestra aquí la racionalidad económica del mundo virreinal, se puede decir que hay una prolongación en dicho pensamiento. Estuvo el ministerio a la altura de los problemas de la época en esta primera fase, todo indica que sí.

La falta de plata para disponer de numerario influyo para que muchas familias notables concurrieran con sus joyas personales para ser fundidas y así tener dinero en efectivo (AGNP/CMR/86/1) la falta de dinero hizo que muchas familias, sobre todo las mujeres cumplieran un papel fundamental. Las cuentas lo confirman, lo que se lleva a acuñar a la caja matriz de Lima son peinetas, aretes, pedazos de cadena de reloj, menudencias de metales precisos, cadenas, sortijas, faluchos, aros, pulseras, pajita, sortijas grandes y pequeńas el texto dice «sortijitas» ((de niñas?), ruedas, azafate con posillos de oro, cucharitas de oro, cajas de reloj con pedacitos, tejos de oro. medallas, hebillas, puños de sable, peinetas, puños de bastón, rielitos, chapitas, mate pie, bombilla, cadena de oros, etc.

El proyecto modernista lo representó el establecimiento de un banco de papel moneda (Camprubi, 2014), según Dionisio de Haro, el banco fue establecido por qué todo indicaba que se conocía el ensayo económico de Alonso Ortiz (Camprubi: 39) ya que el texto de dicho autor había sido reimpreso en lima en 1822, por lo tanto su lectura estaba difundida. La idea del banco era disponer de fondos públicos y así fortalecer en el futuro el crecimiento económico. La formación de bancos de papel moneda en un contexto de moneda metálica, tiene su origen en los vales reales (Tedde, Marichal, 1994: 18), emitidos por el gobierno espańol para obtener de dinero y financiar la guerra con Inglaterra. Los vales reales fueron pensados en ser utilizados como medio de pago, medida que se concretó con la creación del banco de San Carlos en 1782, los vales rendía un $4 \%$ anual.

En 1823 se dispuso la suspensión de los derechos de décima en las ejecuciones civiles.

Se suspendió el cobro de arrendamientos y pensiones. Además de una contribución forzosa para financiar la guerra.

¿Que se entendía por Hacienda pública en aquella época?, se concebía a la Hacienda pública como la entidad encargada de todas las rentas y productos que de acuerdo a la constitución le corresponden al Estado (Dancuart, 1905:1.228). Su existencia y su crecimiento se basaban en una sola regla: el fomento de la actividad productiva. El ministro de la cartera de Hacienda debía presentar anualmente 
al parlamento una descripción general de todas sus oficinas y estructura orgánica, el presupuesto y las contribuciones.

En la memoria ministerial de 1825 se evidencia la economía de guerra en toda su magnitud, la recaudación estaba en crisis, mientras el otro Estado colonial (del rey) que aun sobrevivía, habían destruido la casa de moneda. Financiar la guerra se veía difícil para el gobierno, para garantizar la lealtad de los partidarios de la república, el congreso determino otorgar recompensas por un millón de pesos para el libertador y los jefes militares Memoria 1825). También se dispuso cesar la venta de la bula e cruzada. Se ordenó prohibir la exportación de plata.

En el gobierno de Simón Bolívar los Ministerios se aumentaron a seis: en 1 de junio de 1826 por decreto supremo se establecieron Relaciones exteriores, justicia y negocios eclesiásticos, interior, Guerra y Marina y Hacienda. (Ortega, 1929: LVXXXIII). El Ministerio de Hacienda y Comercio fue reorganizado en 1826, la reforma consistía en hacerse cargo de la contaduría de la casa de la moneda, de la minería, la tesorería general y departamentales y crédito público, cada una de estas secciones estaba a cargo de personal quienes se comunicaban directamente con el ministro. En salvaguarda e la imagen institucional se decretó que las comunicaciones se hicieran por la vía de secciones respectiva.

En agosto de 1826 un decreto supremo reorganiza el ministerio conectando las regiones del interior que estaban obligadas a través de sus tesorerías remitir las cuentas bajo responsabilidad de los prefectos. La racionalidad nueva no fue perdonar nada de las remesas anteriores del gobierno español los cuales fueron recuperados por el gobierno republicano. (Memoria del Ministro (José Morales y Ugalde 1826).

Debido a su carga pesada y el intento de centralización se separó del control ministerial la contaduría general de contribuciones encargada de examinar Las matrículas. El 31 de agosto de 1833 se organizó el tribunal mayor de cuentas, encargándosele tales labores.

De los hechos ocurridos y de las medidas tomadas, se puede entrever que el Ministerio de Hacienda y Comercio recogió las atribuciones de la antigua real hacienda colonial. La idea de las nuevas elites republicanas fue continuar con el modelo centralizador, esto se verifica hasta la guerra de la confederación
Perú boliviana. Respecto al papel que cumplió el sistema financiero hay que decir que una gran mayoría de autores afirman que el feble boliviano estaría detrás de la causa de la guerra de la confederación. Esta afirmación se sustenta en que ante la carencia de pesos fuertes debido a que los mineros exportaban la plata en vez de amonedarla produciendo en el país una escases de pesos fuertes (Salinas: 29) el gobierno intento conservar el peso y ley de la moneda para corregir la devaluación y la circulación del feble. Las medidas del presidente Agustín Gamarra de acuñar 444.000 pesos de feble no hicieron sino agravar la situación del país. Prácticamente la circulación monetaria como base del comercial género una dualidad regional: el norte con una moneda fuerte y el sur con una moneda feble devaluada al valor de la mitad de la primera.

En noviembre de 1827 las finanzas de la republica mostraban pequeños signos de recuperación. Las entradas percibidas por las tesorerías de la republica fueron las siguientes:

$\begin{array}{ll}\text { - Lima: } & 750000 \\ \text { - Ayacucho: } & 137000 \\ \text { - Cuzco: } & 547000 \\ \text { - Puno: } & 102000 \\ \text { - Arequipa: } & 770000 \\ \text { - Libertad: } & 100000 \\ \text { - Junín: } & 300000\end{array}$

(Fuente: Boletín del Ministerio de Hacienda y Comercio, 1962. 31)

Para 1828, la economía no se encontraba muy bien, muchos sectores sociales se encontraban afectados. No solo existían descontentos sociales, sino que se había hecho abuso del cobro de ciertos impuestos, por ello el gobierno del presidente José de la Mar decidió abolir el impuesto del cabezón por ley del 08 de enero de 1828, el argumento ante el congreso fue lo vicioso e inmoderado en el cobro del dicho impuesto, además de ello se dispuso en la ley condonar las deudas del ramo (Santos de Quiroz, 1832: III. 3)

La guerra de la confederación conllevo a la suspensión de, los ministerios de manera temporal, debido las invasiones bolivianas y chilenas. El decreto supremo de 29 de julio de 1839 restableció los antiguos ministerios, Relaciones exteriores, guerra y Marina. 
Las elites comprendieron la necesidad de respaldo institucional. El 21 de diciembre de 1839, se crearon juzgados privativos para conocer en todas las causas en que el estado fuese demandado. Años más tarde la medida muestra como el estado estaba advertido al solicitar los herederos del cargo de fiel de moneda la devolución de la fianza (AGNP/CMR/1871.118).

En 1830 el ministro José María de Pando decretaba solvencia moral en los cargos de dirección, y ser implacables con la evasión fiscal. Es evidente la racionalidad de la institución. Se dispone crear un archivo con sus libros corrientes bajo responsabilidad, los libros eran diario, mayor y auxiliares. Esta disposición en ańos tan tempranos evidencian que existía una cautela de los bienes del Estado, y que se recomienda hacer inventario de bienes y de las oficinas (Ortega: 13), años más tarde el decreto de 01 de marzo de 1841 en el gobierno de Gamarra el cargo de escribano se constituyó en el determinante en el manejo institucional de los papeles y archivo, estaban ordenados en abrir instrumentos públicos siempre en interés del Estado.

En cuanto al personal del Ministerio se dispuso un reglamento de disciplina laboral que todos debían cumplir: ingreso nueve de la mańana retiro a las 2 pm y retorno a las cuatro hasta las seis, es decir en promedio 08 horas efectivas de servicio y dos horas de refrigerio. (Decreto de A. Gamarra: Dancuart, 1905: II).

En el contexto de la confederación Perú boliviana (1837) se ordenó lo siguiente:

- Tratado de comercio y navegación con los Estados Unidos.

- Venta de propiedades del estado.

- Autorizar el comercio en las caletas de Víctor, Sama Ilo, Yerbabuena, Cocotea, Mollendo, Annata y Quilca.

- Establecer el muelle de Arica e yslay.

- Tratado de comercio navegación con Inglaterra.

- Etc.

$\mathrm{Al}$ año siguiente se ordenó los reembarques del azogue, cobro de derechos al oro y plata amonedada, habilitar el comercio del puerto de Chala. Reorganizar la contaduría de valores del Cusco, conceder rebajas a los deudores del Estado.
Las guerras civiles y los golpes de estado podían hacer cambiar la política económica del gobierno afectando a las fuerzas productivas de la época. Por ejemplo la orden del presidente Salaverry al Ministerio de Hacienda y Comercio ordenándole recaudar el impuesto de alcabala de gremios industriales que el gobierno dispuso reestablecer debido a la abolición del impuesto de patentes (Oviedo, 1872: XVI).

El 29 de agosto de 1838, el gobierno paralelo de Agustín gamarra decretó pagar solo la mitad de los sueldos a los empleados de Hacienda y a los de la lista civil, la causa de esta disminución dramática fue por la guerra de la confederación Perú boliviana (Oviedo, 1872: XVI. 231). El año 1839 ante la división producida por la guerra se dispuso la internidad de los empleos del Ministerio de Hacienda y Comercio.

En esta primera etapa se muestra cono las crisis políticas influyen el funcionamiento al interior del ministerio y en el ánimo de los empleados de hacienda. Debido a las guerras de independencia el sueldo de los empleados de hacienda estaban recortados a la mitad. Con la llegada de San Martin y el ministro Hipólito Unanue, se reintegró los sueldos a los empleados. Esta vez por razón de la guerra de la confederación se les amputo medio sueldo, el resultado debió ser traumático en los empleados y debió influir en una mala gestión y corrupción posteriores.

\section{Capitulo 2. El Ministerio de Hacienda y el liberalismo en el gobierno de Ramón Castilla (1845-1862)}

La republica liberal de Ramón Castilla muestra el proceso de modernización del Estado, el proceso de transición con el gobierno de José Rufino de Echenique, fue conflictivo. A partir de 1850 las protestas contra las matriculas de contribuyentes se incrementaron, en Huaraz por ejemplo se acusó a las autoridades de incorporar en la matrícula a ancianos y menores de edad (Salinas, 2018: 22). En el sur específicamente en Huamanga se produjeron tensos debates en cómo aplicar la tasa de impuestos a los indígenas propietarios y o propietarios, estos últimos se encontraban en condiciones similares a las de la Edad Media (Salinas, 2018: 22). Esta época corresponde a la denominada prosperidad falaz del guano. 
El guano de las islas chincha ha pasado a ser concebida como una época de crecimiento sin desarrollo, en donde la políticas publicas emplearon los recursos para la abolición del tributo y de la esclavitud, otra fuente de inversión fue la compra de ferrocarriles y grandes obras públicas. Basadre la calificó como la segunda oportunidad perdida para construir la nación, en donde lo característico fue el derroche fiscal, la corrupción y los gastos burocráticos y militares. Aunque suena contra factual la pregunta que la historia económica ha hecho es ¿pudo industrializarse el Perú?, la escuela liberal afirma que si, el problema es que tenían malas políticas, además de la corrupción. Lo anterior evidencia una práctica económica típica de un Estado rentista. El economista Shane Hunt ha precisado bien estas características al precisar que el Perú durante la Edad del Guano no era una economía de enclave sino más bien una economía rentista, como había sido durante su experiencia colonial, cuando las rentas eran generadas por la plata en vez del guano. Por ello el autor afirma: «La economía rentista está caracterizada por su capacidad para obtener grandes cantidades de divisas a través de la explotación de recursos naturales abundantes...» (HISLA No 4, 1984, p. 61), Conclusiones a las que llega el autor luego de su meditación basándose en el empleo de fuentes de tipo demográfico como el censo de 1876. Como en efecto ha señalado Carlos Contreras (2004), la República del Guano se caracterizó entre otros por sus bases económicamente muy frágiles, pues sobrevivía en términos de fiscalidad de un producto vinculado al mercado externo más que una industrialización interna. En el aspecto social la plutocracia guanera tuvo un medio de expresión a través del periódico El Comercio. En estas épocas la prensa comenzó a tener una mayor participación en las opiniones sobre la hacienda pública permitiéndose hacer recomendaciones sobre la recaudación, censos y matricula de contribuyentes. Sugiriendo al ministro de hacienda Ramón Castilla reordenar la administración de hacienda, levantar un empréstito y reducir los sueldos de la hacienda pública a la mitad (Salinas, 2018: 19). Los reclamos del periódico guardan relación con la crisis posbélica. Las guerras de restauración chilena liquidaron el orden liberal impuesto desde las provincias sureñas como Arequipa que perdieron ingresos ante la desaparición de las rentas de Islay.
En esta etapa se hicieron reformas ministeriales, estableciéndose la Dirección General de Hacienda. Esta fue una oficina general establecida para dirigir la Contabilidad de las tesorerías y oficinas de aduanas den todo el país, su responsabilidad consistía fiscalizar toda la recaudación de la República. La dirección se estableció el 5 de enero de 1848 para reemplazar lo que venía gestionando el Tribunal Mayor de Cuentas que cumplía dichas funciones. Con la nueva dirección el régimen fiscal se modernizo, el tribunal de cuentas estaría involucrado pero solo en la parte judicial, las atribuciones fiscales que daban reservadas para la nueva dirección de hacienda.

El año 1848 fue crucial para el gobierno de Ramón Castilla, aunque la Dirección General de Hacienda fue establecida para conducir racionalmente el gasto, la realidad económica era diferente. El año 1848 mostro una balanza comercial general que mostraba un déficit presupuestario, en la medida en que el estado sobrevivía básicamente por las exportaciones del guano y de los metales preciosos (Rodríguez, 1920 XXI). El desfase es evidente según se desprende del cuadro formado con los datos proporcionados por la Balanza General del Comercio de la Republica peruana del año 1848 :

Cuadro 1

Balanza General de Comercio de importación y exportación para el año 1848

\begin{tabular}{|c|c|c|c|c|}
\hline Productos & Importación & & Exportación & \\
\hline Sedería & 585.038 .3 & $1 / 2$ & 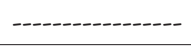 & \\
\hline Lencería & 293.976 .2 & & 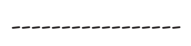 & \\
\hline Algodoneria & 1.681 .853 .6 & $3 / 4$ & 98.476 .0 & \\
\hline Lanas & 911.000 .4 & $3 / 4$ & 184.716 .4 & \\
\hline $\begin{array}{l}\text { Oro, plata, } \\
\text { alhajas }\end{array}$ & 132.878 .6 & $1 / 2$ & 4.553 .588 .3 & \\
\hline Frutas & 68.183 .1 & & 2.069 .1 & \\
\hline Vivieres & 464.957 .3 & $1 / 4$ & 80.013 .6 & \\
\hline Maderas & 114.889 .3 & $1 / 2$ & ---.---.----.-- & \\
\hline Muebles & 95.700 & & & \\
\hline Vinos y licores & 123.596 .4 & & 1.943 .4 & \\
\hline $\begin{array}{l}\text { Artículos } \\
\text { diversos }\end{array}$ & 1.301 .425 .2 & & 477.407 .1 & $1 / 2$ \\
\hline Guano & --.--_-_--_-_-- & & 2.339 .550 & \\
\hline Total & 5.773 .499 .5 & $1 / 4$ & 7.737 .763 & $3 / 4$ \\
\hline
\end{tabular}

(Fuente: Rodríguez, 1920: XXI: 127). 
De la lista de principales productos de exportación destacan dos: el guano y los metales preciosos. El cuadro indica que la dependencia del fisco no giraba en función al recurso guano, sino como en la época colonial en torno a la exportación de los metales preciosos. En la muestra se aprecia que el guano con relación al oro y plata constituye casi el 100\% del valor del guano. Los metales preciosos rendían mucho más que el guano, en una cantidad equivalente demás 2.214.038.3 millones de pesos.

La Dirección General de Hacienda tuvo una duración desde el año 1848 hasta 1855, fecha en que fue extinguida por el decreto del 10 de julio. Suprimida la oficina se vio necesario su reemplazo: se estableció en dicho una sección de cuenta central en el ministerio con las antiguas atribuciones. Sin embargo el congreso de la republica estaba a favor de que la oficina fuese restablecida. Así el año 1859 se dispuso en concordancia por el presidente de la republica que la oficina de la dirección general fuese reestablecida.

Ese mismo año, el 24 de junio se decidió mediante una ley la creación de una sección de estadística en el Ministerio del Interior. Esta sección estadística tenía oficinas subalternas en las capitales del Departamento. Aunque la iniciativa indica que el Estado tenía una visión racional del gasto mediante el empleo de estadísticas por todo el país, el servicio no pudo entrar en reorganización (Rodríguez, 1920: XXI: 127).

La estadística tampoco fue descuidada por el gobierno, el objetivo era contar con información estadística en todo el país, lo que faltaban eran cifras concretas a nivel nacional. En el ańo 1848 el gobierno de Ramón Castilla expidió el primer Reglamento General de Estadística, que cumplía con los requisitos científicos de proporcionar información y ajustado a la realidad sociológica del país. Aunque no pudo aplicarse dicho reglamento, solo pudo establecerse el Consejo Directivo de la Estadística, aportes del gobierno de ramón castilla que recogería más adelante el gobierno de Echenique. Será recién el gobierno civilista de Manuel Pardo y Lavalle, en 1873 se decretó la formación de la Estadística Nacional creándose la Dirección General (Memoria del Ministerio de Hacienda y Comercio1898, XVI).

Para entender este capítulo se debe reseñar la Memoria del Ministro de Hacienda y Comercio
Manuel del Río del año 1847. La memoria se divide en los siguientes rubros informando de manera específica en cada punto:

- Contribuciones directas. Originadas en 1826 se recaudaban solo cuatro tipos de contribuciones: Patentes, indígenas, industria y predios. Recaudación. Diezmos. Contribuciones indirectas. Papel sellado. Moneda. Guano. Deuda publica Ramo de arbitrios. Contabilidad. Tribunal de cuentas.

(Fuente. Memoria del Ministro de Hacienda y Comercio Manuel del Río del año1847)

De todas las contribuciones directas destacaba la de Patentes, la cual fue establecida el 10 de agosto del año 1826. La contribución estaba vinculada a la producción oficial de casas y talleres y tenía importancia decisiva en la industria gremial. El ministro en un afán modernista cuestionaba la contribución de indígenas por ser un impuesto anacrónico además de odioso para la población ya que tenía una raigambre colonial, sin embargo a pesar de lo negativo para los indios, la contribución fue aceptaba, se había pensado que permitirles el acceso a la propiedad, dándoles la tierra podría mejorar su situación. Sin embargo la memoria indica que el gobierno al darles la propiedad de la tierra había empeorado su situación. Esto muestra que el transito económico desde la época virreinal hasta la época republicana, estaba casi fija y permanente en el tiempo. En cuanto a los predios urbanos se imponía una contribución de un 3\% a la propiedad rustica y un $4 \%$ a la propiedad urbana.

En lo que respecta a la recaudación el ministro reconoce que la población se negaba a pagar sus respectivas obligaciones, sin embargo las medidas adoptadas en todo el país obligaba en el interior por ejemplo a los consejos distritales encargarse al respecto.

Los diezmos, obligaba a los agricultores a pagar al Estado, es concebido como un mal por ser forzosa contra los hacendados.

En cuanto a la contribución indirecta, las aduanas imponían los gravámenes. Entre las dificultades encontradas se encontraba lo enorme de la costa peruana y la disparidad regional, por ello lo más difícil era aplicar el reglamento de comercio de manera horizontal entre las zonas dedicadas al comercio. Todos 
esos factores hacían pensar que debía proponerse un nuevo reglamento.

En cuanto al papel sellado, se recomienda elevar la contribución debido a que daban seguridad a los contratos y actos civiles, asequible a toda la población.

Sobre la moneda, el peso, el problema principal fue la calidad de la moneda cambiada por el gobierno boliviano quien subdividió los pesos fuertes dando origen a una moneda débil, esta tenía mucha presencia en los mercados del sur, haciendo inviable su aceptación. Esta moneda conocida como feble seguía acuñándose por el gobierno boliviano.

En lo concerniente al guano, para 1840 , se observó una especulación en su comercialización. Ante el hecho el gobierno en 1840 se inició una contrata con Francisco Quiroz. Muchos factores habrían ocasionado problemas de comercialización y disminución. Por ejemplo el hallazgo de guano en África y Patagonia paralizó la exportación del producto, lo mismo el clima desfavorable como fue el año 1845 en donde la extrema sequedad desanimó a los agricultores para su compra.

La deuda pública era considerada un problema social, por el tema de la deuda interna, el congreso tenía que ponerse de acuerdo para poder hacer frente al gasto a pagar a los acreedores.

El ramo de arbitrios. El problema principal era la deuda que tenía el gobierno a la caja por razón de préstamos durante la guerra civil del año 1834 .

La contabilidad. Fundamental para descubrir los fraudes y colusiones en perjuicio del estado. El sistema heredado de la época virreinal aspiraba establecer un sistema contable más fuerte en la fiscalización, algo cercano al sistema de partida doble que durante el virreinato se aplicó, pero solo duro poco tiempo debido a la fuerte oposición. En el año 1830 se intentó aplicar dicho sistema pero tuvo una ferra oposición de las oficinas. El ministro viendo estas dificultades le propone al congreso se apruebe la creación de la Tesorería Departamental de Lima en reemplazo de la tesorería general por ser inservible.

Finalmente, el tribunal de cuentas encargada del control de la contabilidad de la república,

Su función principal que consistía en finiquitar las cuentas de las cajas reales en la época virreinal, y de las tesorerías en la época republicana, no llegaba a cumplir su función. Se confundía su atribución judicial con su función administrativa. Debido a ello, en 1826 se la cambio de nombre como Contaduría General de Valores, el problema principal fue que al seguir con su atribución judicial demoraba en finiquitar las cuentas, además de significar un gasto mayor. Por dicho problema se decidió restituirle su antiguo nombre como Tribunal de Cuentas en 1839. Sin embargo aún no estaban claras la política del gobierno por lo que le cambio de denominación en 1840 bajo el membrete Dirección de Hacienda y Contaduría General. Si en 1839 gastaba 40.000 pesos anuales en 1840 aumento a 1841 por el incremento de algunos empelados en sus instalaciones.

Finalmente se puede decir que los problemas fiscales del país, muestran un interés por establecer bases sólidas a partir del reconocimiento y diagnóstico de la economía fiscal, para que el congreso le dé su debida solución.

Castilla asumió una postura descentralista ministerial, para poner en sintonía a los ministerios de estado con las nuevas necesidades públicas, el gobierno decidió organizar los ministerios mediante el decreto de primero de febrero de 1855, separando el Ministerio de Hacienda y Comercio, del ministerio de justicia y beneficencia, ya que antes se encontraban fusionados. El nuevo ministro de hacienda seria el ciudadano Domingo Elías.

La organización del Ministerio de Hacienda alcanzo también a los demás ministerios, todos fueron organizados el 17 de noviembre de 1856. Era la fase liberal del gobierno, algo que no gustaba a los sectores conservadores de la república. En un contexto de rebelión al mando del general Vivanco, se produjo la victoria en Arequipa, pacificado el país el gobierno decidió promulgar la constitución de 1860 de tendencia moderada. La ley del 17 de marzo colisionaba con las nuevas disposiciones de la carta magna. Por esta razón se dictó la ley ministerial el 02 de Mayo de 1861, modificada en 1865 . El principal cambio fue institucional, al incorporarse las memorias en la constitución.

Estas políticas desarrollistas del gobierno castillista, tuvieron un alto costo social el tráfico humano de población asiática proveniente de china. El comercio o tráfico de chinos e inicio en el Callao cuando la barca dinamarquesa Federico Guillermo trajo 75 chinos, de allí, su número fue en aumento. De acuerdo a la estadística de Garland, la inmigración china al Perú fue en el siguiente proceso: 


\begin{tabular}{|c|c|c|c|c|c|c|c|c|}
\hline 1849 & 1853 & 1856 & 1859 & 1862 & 1865 & 1868 & 1871 & 1874 \\
\hline 75 & 4366 & 5000 & 3000 & 1008 & 4540 & 4266 & 11812 & 3285 \\
\hline
\end{tabular}

Fuente Garland, ob. cit.

En total contando año por año se importaron del Asia en virtud de la ley de inmigración asiática la cantidad de 87.343 coolies. Las características que tuvo el proceso de inmigración fue de practicar con ellos relaciones de trabajo casi esclavo como afirma Cecilia Méndez y Humberto Rodríguez Pastor.

\section{Discusión}

En cuanto al objetivo principal de la investigación, la primera discusión conlleva a determinar lo siguiente: primero, en lo que respecta al Ministerio de Hacienda y Comercio Javier Tantaleán (1983), solo menciona que existe un Estado de Jure (caudillista y guanero), es decir de acuerdo a ley considera que es liberal, y otro estado y economía que es pre capitalista, lo que impedía cualquier desarrollo. Carlos Contreras (2012) considera que el Estado era centralizado y clasificado sectorial y funcionalmente (183), como institución el Ministerio de Hacienda y Comercio habría tenido poco desarrollo hasta el momento de la guerra con Chile debido a que estaba en manos de los guaneros y salitreros, su personal se encontraban diseminados por casi todas las cajas fiscales. No tenía cuerpo de cobradores "su alta burocracia» siempre estuvo a manos de hombres de negocio más que de hombres dedicados a la guerra (Contreras, 2013:184). Respecto a la fiscalidad hacendaria, para el autor es clave su estudio para comprender dicho proceso. Su recomendación es que el estudio de la fiscalidad pública se constituye en una fisiología del Estado que proporciona a los historiadores una serie de indicadores fundamentales para comprender el proceso económico del siglo XIX. A título personal considero que el desarrollo ministerial inicia su modernización antes de la guerra con Chile en el gobierno de Ramón Castilla y posteriormente con José Balta en la época del guano.

En cuanto al objetivo específico de aproximarse a la economía peruana del siglo XIx, en general dos corrientes historiográficas han signado la historia económica del Perú en el siglo xIx, la escuela liberal y la escuela dependentista. Hasta los años 80 la imagen construida por la historiografía peruana del Perú hasta 1900 era la de ser un país articulado a los intereses del gran capital financiero. En esta perspectiva se encontraban los autores como Pablo Macera, Ernesto Yepes, Heraclio Bonilla y Javier Tantalea (Quiroz, 2010: 67). Las causas que dejaron de lado los estudios del pensamiento político de la Republica en el siglo XIX estarían principalmente influenciadas por la historiografía "dependentista» de los años 70", que partiendo de la teoría de la dominación imperial sostenía la inexistencia de proyectos nacionales de carácter modernista en el Perú.

La historiografía en mención, consideraba a la República postcolonial como un país sujeto en lo económico a ser un apéndice del llamado imperialismo decimonónico dirigido por la Gran Bretaña (Bonilla, Yepes). La teoría enunciada tiene fundamentos históricos, pero colisionan con el estudio del Ministerio de Hacienda y Comercio que fue entre todas las instituciones que si participo en los ámbitos necesarios mediante el control y la fiscalización, en donde los ministros de Estado (miembros de las élites nacionales) pensaban hacía falta ordenar las finanzas del Estado. El Ministerio de Hacienda y Comercio cumplió un papel fundamental para la construcción de las finanzas del Estado caudillista, al constituirse en un mecanismo del poder en aras de la construcción de la política y de la nación al momento de fundarse la república. Como sostiene Ulrich Mucke (1998) «para comprender mejor la historia del siglo pasado (s. XIX), se requieren estudios sobre la política de su época», esto sugiere estudiar el sistema electoral, sus instituciones, parlamento y administración pública, como también a los actores sociales presentes en la burocracia, como indicadores de los variados intentos por construir la nación desde el Estado peruano.

\section{Conclusión}

Así como la sociedad se rige por comunidades atomizadas, en donde no se puede vivir solo o aislado (Ksenofon, 2017: 35), también el hombre se rige por 
el funcionamiento de sus instituciones. El Ministerio de Hacienda y Comercio fue la entidad pública más importante después del gobierno presidencial, fue la institución esencial que estuvo bajo control de las elites dominantes empeñadas en constituir un Estado nacional fuerte que expresara sus intereses. Los Ministros de estado fueron miembros del sector oligárquico dominante.

Existe una racionalidad en los dispositivos emitidos por el Ministerio de Hacienda y Comercio para organizar el Estado republicano a través de la política del gasto y financiamiento.

La reorganización del ministerio de Hacienda fue necesaria para solucionar las crisis fiscales y para ordenar la administración por el crecimiento guanero. En este sentido fue necesario reorganizar la Secretaria de Hacienda y el Tribunal Mayor de Cuentas, esto permitió un mayor control por parte del Estado en el plano fiscal.

La corrupción afecto el desarrollo e dichas instituciones. El Ministerio de Hacienda y Comercio como parte de la Administración del naciente Estado, surge como una institución fiscal considerada como el eje sustancial del cuerpo de la república, a través del puesto un mecanismo de ascenso social, debido a que los nuevos funcionarios públicos practicaron una política de desfalcos a la institución, que incluso pusieron en peligro las rentas fiscales de la República.

\section{Fuentes utilizadas}

Archivo General de la Nación. Sección Casa de Moneda república

Archivo General de la Nación. Sección Tribunal del Consulado. Republica

\section{Fuentes editas siglo XIX-XX}

Boletín del archivo histórico del Ministerio de Hacienda y Comercio.

Constitución Política del Perú. Perú Constitución 1828. Lima: Imp. de Juan Masías, 1828.

Constitución Política del Perú. Lima: Imp. de Juan Masías, 1834.

Constitución Política de la Republica Peruana. Constitución 1839. Lima: Imp. de Juan Masías, 1839.
Constitución Política del Perú de 1856. Lima: Imp. de J. F. Moreno, 1856.

Constitución Política del Perú 1860. Lima: Imp. de Juan Masías, 1860.

Contestación del general Manuel de la Guarda ex ministro de guerra a los trece diputados en su cámara achacando al gabinete cesante de traición a la confianza pública. Lima: 1864.

Garland, Alejandro (1905) Reseńa industrial del Perú. Lima: Ministerio de Fomento

Lara Ch. E. G. (1936) historia del Ministerio de fomento y obras públicas. Lima Perú.a

León y León, Federico (1897) Tratado de derecho administrativo. Lima Moreno editor.

Memoria de la Dirección General de Rentas al Ministerio de Hacienda y Comercio. Lima 1878. Imprenta de la calle de la rifa.

Orinuela, José (1825) Edicto del ilustrísimo y reverendo José Calixto de Orihuela dirigido a su fieles para el goce de las gracias concedidas en la Bula de Cruzada... Lima. Imprenta republicana 1825

Ortega Zegarra, Joaquín (1929) Digesto de Hacienda en el Perú Lima Casa Nacional de Moneda.

Santos Quiroz, Mariano (1832) Colección de leyes, decretos y órdenes: publicadas en el Perú desde su independencia el ańo 1821 hasta 31 de diciembre de 1830. Lima, imprenta de José Masías. 3 volúmenes.

Oviedo, Juan (1872) Colección de leyes, decretos y órdenes: publicadas en el Perú desde el año 1821 hasta 31 de diciembre de 1839. Lima, Manuel A. Fuentes.

\section{Referencias bibliográficas}

BASADRE, Jorge (1971). Introducción a las bases documentales del Perú. Lima: Editorial P.L.V., 1971, 2 T.

Basadre, Jorge (1969). Historia de la República del Perú. Sexta Edición. Lima: Editorial Universitaria.

BASADRE, Jorge (1930). La iniciación de la república. Lima.

Basadre, Jorge (2005). Historia de la república del Perú. Lima: El Comercio.

BazÁn, Mario (1954). El proceso económico en el Perú. Buenos Aires: Editorial Mundo América.

Bonilla, Heraclio (1974). Guano y burguesía en el Perú. Primera Edición. Lima: Instituto de Estudios Peruanos. Cambrubi, Carlos (2014). El banco de la emancipación. Lima BCRP. IEP. Estudio introductorio de Dionisio Romero Haro. 
Cisneros, Luis Benjamín (1939). Obras completas. Lima. Tomo III. Política-finanzas-obras públicas-instrucción. Contreras, Carlos (2012). La economía pública en el Perú después del guano y el salitre. Crisis fiscal y elites económicas durante su primer siglo Independiente. Lima: BCRP-IEP.

Contreras, Carlos (2010). Guerra, finanzas y regiones en la historia económica el Perú. Lima. BCRP-IEP:

Contreras, Carlos (2011). El aporte de Shane Hunt al estudio de la economía peruana y de su proceso histórico. Economía Vol. XXXIV, № 67, semestre enero-junio 2011, pp. 212-218 / ISSN 0254-4415.

Contreras, Carlos (2004). El aprendizaje del capitalismo. Estudios de historia económica y social del Perú republicano. Lima: Instituto de Estudios Peruanos.

Contreras, Carlos (2016). El nacional liberalismo del economista peruano José Manuel Rodríguez, 18571936. Am. Lat. Hist. Econ., año 23, núm. 1, eneroabril, pp. 41-67.

Dancuart, Pedro Emilio; Rodríguez, José Manuel. (19031908). Anales de la Hacienda Pública del Perú. Leyes, Decretos, Reglamentos y Resoluciones, Aranceles, Presupuestos, Cuentas y Contratas, que constituyen la legislación y la historia fiscal de la República. Lima: Imp. del Estado.

García Calderón, Francisco (1879). Diccionario de la Legislación Peruana. Segunda edición, Paris. 2 tomos.

Mesones, Luis (1859). El Ministerio de Hacienda en el Perú en sus relaciones con los administradores del guano en Europa. Bezanzon: Imp. De José Joaquín.

Morales, Carlos (2007). Fuentes para el estudio del ministerio de Hacienda y Comercio. Lima: Illapa.

Morales, Carlos (2013). Fiscalidad real, monedas, rentas e impuestos coloniales en el virreinato del Perú (Siglo XVIII)

Osores, José Manuel (1866). Causas económicas de la decadencia de la república y medidas que podrán adaptarse para mejorar la situación. Lima: 1886.

O'Phelan Godoy, Scarlett; Georges Lomne (eds.) (2014). Voces americanas en las Cortes de Cádiz: 1810-1814. Lima: IFEA-PUCP.

Paz Soldán, Mariano Felipe (1879). Biblioteca Peruana. Lima: Imp. Liberal, 1.

Porras Barrenechea, Raúl (2018). Fuentes históricas peruanas. Lima: Fundación Bustamante de la Fuente.

Quiroz, Alfonso (1987). Las deudas defraudadas. Consolidación de 1850 y dominio económico en el Perú. Primera edición. Lima: INC.
Quiroz, Alfonso (2017). Crédito inversión y políticas públicas en el Perú entre los siglos XVIII-XX. Lima: BCRP-IEP. Quiroz, Francisco (2010). Guerra, finanzas, y regiones en la historia económica del Perú. Lima: BCRP-IEP.

Rodríguez, José Manuel (1895). Estudios económicos y financieros y ojeada sobre la hacienda pública del Perú y la necesidad de su reforma. Lima.

Rodríguez, José Manuel (1920). Anales de la Hacienda Pública del Perú. Leyes, decretos, reglamentos y resoluciones. Aranceles, presupuestos, cuentas y contratas, que constituyen la legislación y la historia fiscal de la República. Lima: Imp. del Estado.

Rodríguez, Jaime (1998). La independencia de la América española. México: FCE.

Romero, Emilio (1949). Historia económica del Perú. Buenos Aires: Editorial Sudamericana.

Salas Olivari, Miriam (2016). El presupuesto, el estado y la nación en el Perú decimonónico y la corrupción institucionalizada, 1823-1879. Lima: Instituto de Estudios Marítimos del Perú.

Salas Olivari, Miriam (2011). Historia marítima del Perú. Vol. 11. La República - 1879 a 1883 /. Lima: Instituto de Estudios Histórico-Marítimos del Perú.

Salas Olivari, Miriam (2012). Convergencia y divergencia en las economías de Perú, Bolivia, chile e Inglaterra antes de la guerra del Pacífico, 1810-1879. En Nueva corónica 1 (Enero, 2013) ISSN 2306-1715

SAGredo, Rafael (2014). Cádiz, el orden civil y la presentación política, propuestas y proyecciones. En: O,Phelan Godoy Scarlett, Georges Lomne (eds.), Voces americanas en las Cortes de Cádiz: 1810-1814. Lima: IFEA. PUCP, pp. 339-350.

Salinas, Alejandro (2018). La economía peruana vista desde las páginas del comercio, silgo XIX. Lima: Banco Central de Reserva del Perú. Instituto de Estudios Peruanos.

Tantaleán Arbulú, Javier (1983). Política económica financiera y la formación del Estado. Siglo XIX. CEDEP.

Tedde, Pedro; Marichal, Carlos (Coords.) (1994). La formación de los bancos centrales en España y América. Siglo $X I X-X X$.

Yépez del Castillo, Ernesto (1981). Perú 1820-1920. Un siglo de desarrollo capitalista. Lima: Editorial Signo. 